
(C) 2017, Elsevier. Licensed under the Creative Commons Attribution-NonCommercial-NoDerivatives 4.0 International

http://creativecommons.org/licenses/by-nc-nd/4.0/

\title{
Combined Heat and Power from the Intermediate Pyrolysis of Biomass Materials: Performance, Economics and Environmental Impact
}

\author{
Y. Yang a ${ }^{\text {a }}$ J. G. Brammer ${ }^{\text {b }}$, D. G. Wright ${ }^{\text {a }}$, J. A. Scott ${ }^{\text {a }}$, C. Serrano ${ }^{\text {a }}$ and A.V. Bridgwater ${ }^{\text {a }}$ \\ ${ }^{a}$ European Bioenergy Research Institute, Aston University, Birmingham B4 7ET, UK \\ ${ }^{b}$ Department of Chemical Engineering, University of Chester, Thornton Science Park, Chester CH2 4NU, UK
}

\begin{abstract}
Combined heat and power from the intermediate pyrolysis of biomass materials offers flexible, on-demand renewable energy with some significant advantages over other renewable routes. To maximise the deployment of this technology an understanding of the dynamics and sensitivities of such a system is required. In the present work the system performance, economics and life-cycle environmental impact is analysed with the aid of the process simulation software Aspen Plus. Under the base conditions for the UK, such schemes are not currently economically competitive with energy and char products produced from conventional means. However, under certain scenarios as modelled using a sensitivity analysis this technology can compete and can therefore potentially contribute to the energy and resource sustainability of the economy, particularly in onsite applications with low-value waste feedstocks. The major areas for potential performance improvement are in reactor cost reductions, the reliable use of waste feedstocks and a high value end use for the char by-product from pyrolysis.
\end{abstract}

Keywords: bioenergy system; intermediate pyrolysis; combined heat and power; technoeconomic evaluation; environmental life-cycle analysis

\section{Introduction}

\subsection{Background}

Over ten percent of total world primary energy supply in 2013 (13.5 billion tonnes of oil equivalent) was produced from biomass sources, making biomass by far the most important renewable energy source [1,2]. In a global context, the use of biomass to generate power and heat has been a key element in reducing fossil fuel consumption and combating climate change. In the UK, the government has projected bioenergy to contribute over $35 \%$ of the total renewable energy production (including non-domestic heat and transport) needed to meet the target of $15 \%$ primary energy generation from renewables by 2020 [3].

Biomass as an energy source is abundant, predictable and non-intermittent, and, importantly, is 
largely "carbon neutral" if sustainably managed. Furthermore it is the only alternative source of fixed carbon for the manufacture of carbon based fuels and chemicals. Over the past 35 years, converting solid biomass material to liquid and gaseous biofuels through thermal conversion processes (pyrolysis and gasification) has been attracting attention both for scientific research and for industrial commercialisation, as they are considered as promising technologies for cleaner energy production [4-8]. Pyrolysis is a thermal process in which an organic feedstock decomposes at elevated temperatures (usually between 450 and $550^{\circ} \mathrm{C}$ ) in the absence of oxygen. Three product phases are simultaneously produced, namely pyrolysis liquid (consists of pyrolysis bio-oil and pyrolysis water), combustible gases and char with potential for fuel applications. The pyrolysis liquid is particularly interesting, as it is an efficient energy carrier due to high energy density and has the advantage of application in engines [9]. Combined Heat and Power (CHP) is an effective and efficient method of energy production as it simultaneously generates electrical power and heat (in the form of steam or hot water) in a single process. Diesel engine based stationary generating systems generally have high fuel quality tolerance and can use liquid biofuel. In a typical diesel engine CHP arrangement, approximately $45 \%$ of the total energy input is recoverable as heat from the engine cooling and exhaust gas system in the form of hot water and approximately $40 \%$ is converted to electricity. This "co-generation" method therefore uses much less fuel compared to the separate generation of power and heat [10].

Research and technology development of integrated biomass pyrolysis and CHP process has attracted attentions in the recent a few years. Kohl et al [11] investigated the integration of biomass fast pyrolysis within a CHP plant. The results showed that the process integration strongly improved the CHP's energetic and environmental performances. The operation hour of the plant can be increased by up to $57 \%$ by providing lower district heating loads. When concerning the optimisation of district heating energy efficiency, the authors concluded the pyrolysis products (oil and char) should be sold to market rather than internal use. Van de Beld et al [12] carried out a series of experimental investigations into the use of pyrolysis oils and pyrolysis oil derived fuels in diesel engines for CHP applications. A duration experiment of 40 hours with pyrolysis oils was carried out without notable negative effect on exhaust gas emissions and fuel consumption [13]. Despite satisfactory results achieved, the authors also pointed out that some specific properties of the oils (e.g. low heating value, low ignition ability, high water content and high sensitivity to 
repolymerisation) caused difficulties in direct diesel engine applications. These aspects needed to be taken into consideration when upgrading the oils for improvement. Industrial development of the integrated biomass pyrolysis and CHP plant was firstly demonstrated by Fortum Oyj. in 2013 at Joensuu Finland [14]. A fast pyrolysis system (50,000 litre/year fast pyrolysis oil) has been integrated to a CHP system with a production capacity of $50 \mathrm{MW}$ for electrical power and 140 MW for heat (mainly district heating power). The pyrolysis oils produced are consumed on-site to replace heavy fuel oil, which equals to about 10MW in energy production [14].

As with any novel energy system, it is necessary to understand the overall performance and environmental and economic impacts of schemes at various scales to ensure that effort and investment are targeted at the areas of greatest potential impact. Techno-economic and environmental assessments of pyrolysis to energy systems are being increasingly undertaken with recent contributions in the area of small scale power generation by Shemfe et al [15], and CHP from fast pyrolysis by Rogers et al [16] and Bridgwater et al [17]. Exergoeconomic assessment of CHP-integrated biomass upgrading were carried out by Kohl et al [18] to evaluated the energy efficiency and energy production cost on using different feedstocks and integration options. Consideration of non-energy applications of pyrolysis is an increasingly important aspect of this work as discussed by Kuppens et al [19] who examine phytoremediation as an alternative motivation for developing pyrolysis projects.

\subsection{The intermediate pyrolysis process}

Development of a pilot-scale intermediate pyrolysis technology commenced at Aston University in 2008. A larger scale technology demonstration started in 2012 (maximum $100 \mathrm{~kg} / \mathrm{h}$ throughput - Figure 1). The core of the intermediate pyrolysis system is a co-axial dual (inner screw and outer) screw pyrolysis reactor, which operates in a temperature range of $450-550^{\circ} \mathrm{C}$ and with a much longer solids residence time (2-10 minutes) compared to conventional fast pyrolysis (detailed design features can be found in [20,21]). Depending on the type of feedstock and processing conditions, the product yields are 10-30\% liquid (pyrolysis oil and water), 15-20\% gas and 50$75 \%$ char. During reactor operation, the inner screw conveys a mixture of fresh feedstock and recycled char product forward through the reactor, and the outer screw returns a portion of the char 
product backwards for recycle to achieve internal char recycling. Hot recycled char can act both as the heat carrier and as the catalytic cracking medium (due to the presence of ash in the char [22]) thereby enhancing the secondary cracking reactions for pyrolysis vapours. This results in the production of a greater fraction of permanent gases and lower molecular weight condensable organic components and less heavy tars.

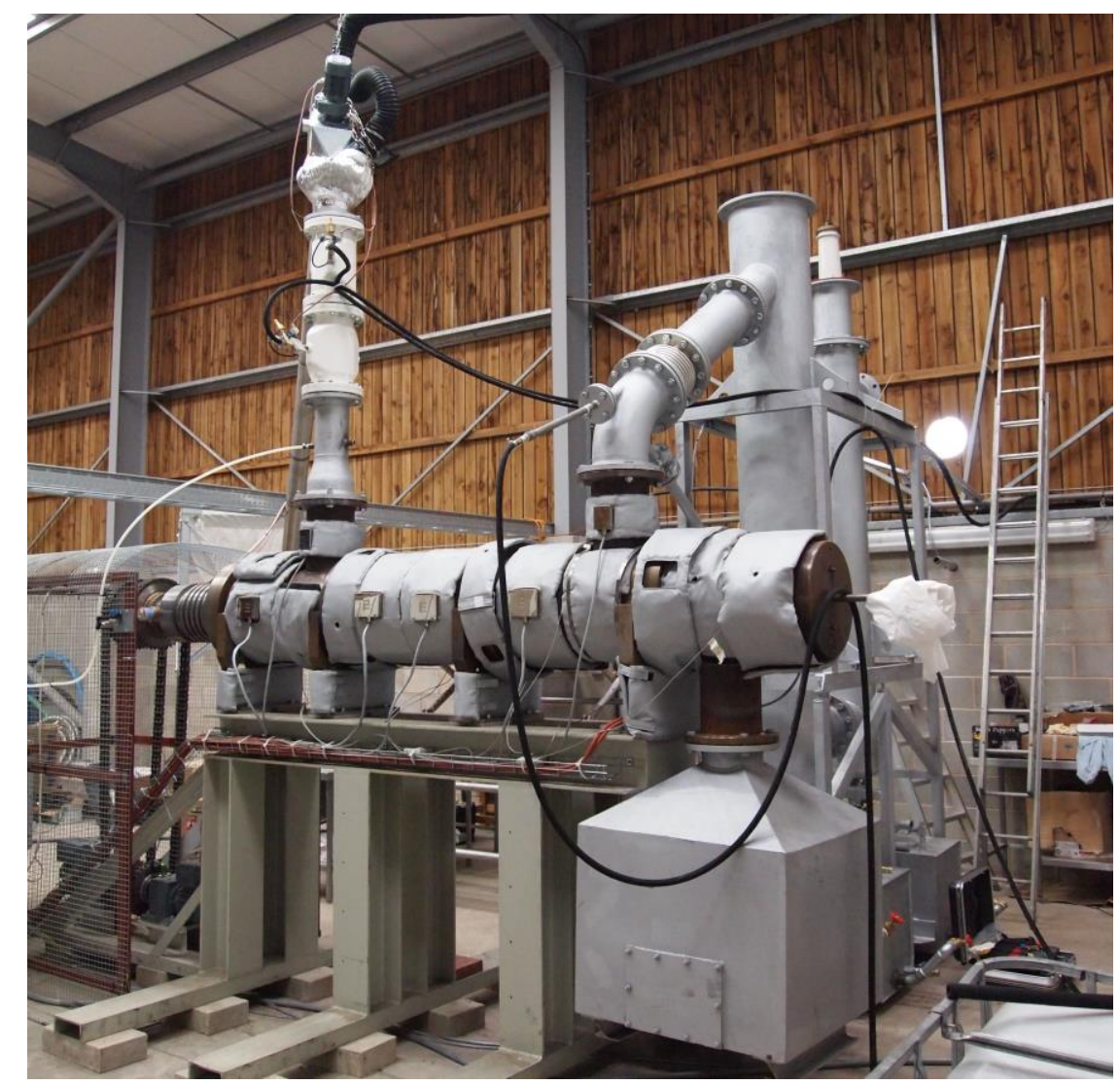

Figure 1. Intermediate pyrolysis system development at Aston University

Despite the relatively low liquid yield compared to conventional fast pyrolysis which is designed to maximise this yield, the intermediate pyrolysis process may deliver superior overall performance when the quality of all the products of pyrolysis are considered. The products are in three forms.

(1) A two phase liquid where the organic phase (pyrolysis oil) can be easily separated from an aqueous phase under gravity. The pyrolysis oils, in blends with up to $50 \%$ biodiesel, can be 
used in unmodified diesel engines for heat and power [21,23,24].

(2) A valuable char product which can be used as charcoal for combustion or bio-char as a soil enhancer. If processing high-moisture content feedstocks, the char can acquire the characteristics of activated carbon due to comprehensive interaction with steam [25].

(3) A high-quality fuel gas that contains over $50 \%$ combustible gases $\left(\mathrm{H}_{2}, \mathrm{CH}_{4}\right.$ and $\left.\mathrm{CO}\right)$ with the reminder mainly being $\mathrm{CO}_{2}$ [21]. The screw-based reactor usually does not require large quantities of inert gas (usually nitrogen) as a transport or fluidising medium (as is the case with the conventional fluidised bed pyrolysis reactors), which normally remains as a part of pyrolysis gas and causes dilution of pyrolysis gas with reduced heating value.

Furthermore, the intermediate pyrolysis reactor can process difficult low-value high-ash waste feedstocks (such as sewage sludge and de-inking sludge) that cannot be processed by fast pyrolysis, as reported by previous work on pilot-scale investigation [23,24]. This is due to the fact that the reactor is based on screw conveyers rather than gas/liquid fluidisation.

\subsection{Aim of the work}

As described in the last section, the intermediate pyrolysis technology is originally developed at Aston University. There has been a series of laboratory based experiment carried out from bench to pilot scale investigating the production of pyrolysis oils and other products for energy application purpose. Following the previous work, this work evaluates the integrated fuel production and energy production systems with consideration of technical, economic and environmental aspects. The originality of this work is presenting a performance model for the novel intermediate pyrolysis and CHP system (hereafter referred as Pyro-CHP), which is developed based on the results from previous experimental work and executed by using the Aspen Plus process simulation software. The energy balance and CHP efficiencies for the engine subsystem and the overall Pyro-CHP system are calculated by the process model for difference system scales. These results of system performance are then utilised in a comprehensive economic evaluation for calculating the Levelised Electricity Cost (LEC) by this integrated novel system. A sensitivity analysis is performed to examine the impact of aspect range of factors and the optimum LECs are calculated. Finally, the life-cycle GHG emissions associated with operating the system 
and the total GHG savings available are calculated. The present work is the first time that intermediate pyrolysis in combination with CHP has been evaluated for economic and environmental performance. The work identifies the major opportunities for performance improvements and highlights the effects of system scale, feedstock choice and co-product (char) economics.

\section{Performance model of the Pyro-CHP system}

This section presents the performance model formulation, the limits of the model scope and details of assumptions made related to the technical aspects of the modelled system. Following this, Section 3 shows the equivalent for the economic modelling and Section 4 for the environmental and life-cycle assessment modelling.

\subsection{Model limits}

This simulation model calculates the efficiencies of utilising prepared wood feedstock (wood pellets) to produce power and heat. The feedstock is processed in an intermediate pyrolysis reactor to form pyrolysis liquid, gas and char product. The liquid fraction is then blended with biodiesel before combustion in a diesel engine based generating system for energy production. The starting point of the model is the entry of the prepared feedstock into the pyrolysis reactor feeding system. The end points of the model are: 1) the output of the electricity and heat from the engine CHP system and 2) the output of biochar to the char collecting vessel. Downstream use of the char and energy products are outside of the model scope. This model is applicable to the UK.

\subsection{The Pyro-CHP system}

The proposed Pyro-CHP (Pyrolysis-Combined Heat and Power) system is shown in Figure 2, and incorporates an intermediate pyrolysis system with a diesel engine-based CHP system. The pyrolysis system consists of a biomass feeder, an intermediate pyrolysis reactor, a gas/char combustor, a vapour condenser and liquid separation system. The CHP system consists of a diesel engine generator, a shell and tube heat exchanger for the cooling system and a shell and tube heat exchanger for the exhaust gas. Experimental results of the mass balance and pyrolysis product 
properties from the pilot-scale intermediate pyrolysis system [21,26] and of diesel engine performance (including input of flow rates and temperatures for air, fuel and cooling water and output of flow rate and temperature for exhaust gas) running blends of biodiesel and pyrolysis oil [23] are used as inputs in the Aspen Plus simulation to calculate the engine energy balance and overall system energy balance. Scale effects have been incorporated when calculating the engine's electrical and heat efficiencies [27].

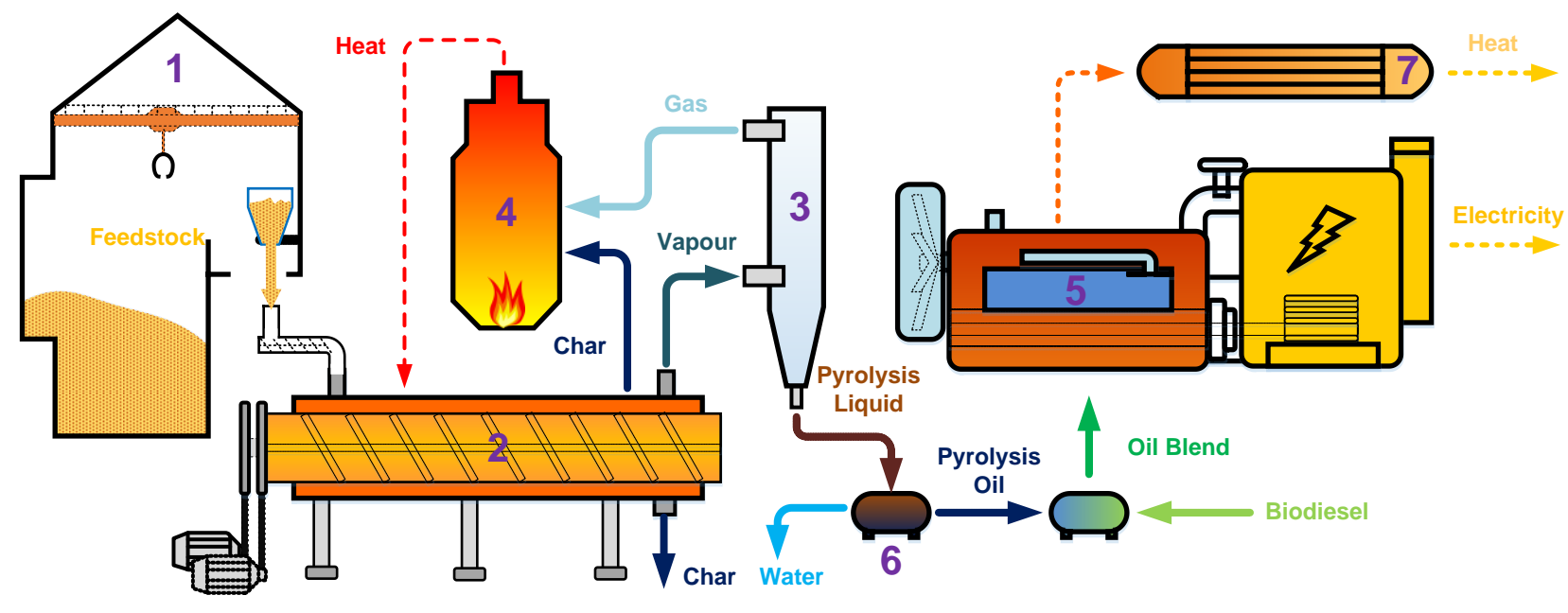

Figure 2: Schematic diagram of the proposed Pyro-CHP system

(1. Feedstock storage; 2. Intermediate pyrolysis reactor; 3. Condenser; 4. Char/gas; combustor; 5. Diesel CHP engine; 6. Liquid separation; 7. Heat exchanger)

The chemical process simulation software Aspen Plus (V8.3) was used for calculating the process energy balances for the Pyro-CHP system (for flowsheet with detailed model description see Supporting Information). The wood energy pellets (defined as non-conventional particles with size distribution 5-15 $\mathrm{mm}$ ) are firstly processed by a pyrolysis module (RStoic reactor, using predefined feedstock decomposition reaction that is derived from the results of product analysis from real experiments) at a feeding rate of 200, 600 or $1000 \mathrm{~kg} / \mathrm{h}$ (shown as item 2 in Figure 2). The biomass is converted into pyrolysis vapour (a vapour and gas mixture including a number of oxygenated hydrocarbon organics, water, $\mathrm{CO}_{2}, \mathrm{CO}, \mathrm{CH}_{4}$ and $\mathrm{H}_{2}$ etc.) and char (mixture of carbon and ash). The hot vapour stream passes through a condensation and a separation module. The organic fraction is separated from the aqueous fraction to form pyrolysis oil (a mixture of a number 
of oxygenated hydrocarbon organics). The oil is then blended with biodiesel in 50/50 volumetric ratio for engine use (RStoic reactor). All permanent gases and $10 \mathrm{wt} \%$ of char produced by the pyrolysis module are consumed onsite in a gas and char combustor for heat production, which is enough to meet the heat demand of the pyrolysis module. The CHP engine generates electrical power and recovers heat from the engine cooling system and exhaust system respectively in the form of hot water. The electrical power, heat and surplus char are the final products available for sale.

The following assumptions have been made in this model:

- The Pyro-CHP system operates continuously in a steady-state condition.

- The combustion reaction is complete (only $\mathrm{CO}_{2}$ and $\mathrm{H}_{2} \mathrm{O}$ are found in the exhaust gas).

- The environmental temperature and pressure are $20^{\circ} \mathrm{C}$ and $101.325 \mathrm{kPa}$, respectively.

\subsection{Feedstocks}

The woody feedstock used in this work is wood fuel pellets supplied by a UK commercial supplier [28]. The pellets consist of compressed pine sawdust or ground pine chips, having a nominal size of approximately $5 \mathrm{~mm}$ in diameter and $15 \mathrm{~mm}$ in length. The moisture content of these wood pellets is about 8 wt.\%. Characteristics of the feedstocks are shown in Table 5 (Section 5.1). Although have a high cost, wood pellet is selected as feedstock as it has high bulk density and energy content and good consistency in composition.

\section{Economic evaluation model}

\subsection{General assumptions}

The base year for this study is 2014. All data have been updated using an inflation rate of $3 \%$ to present costs in British Pound Sterling [17]. The evaluation assumes UK installations around the Midlands area. The assumed annual plant operating time is 8000 hours [29]. The total project life is taken to be 20 years. 
Pyro-CHP systems are evaluated at three different capacities: 200, 600 and $1000 \mathrm{~kg} / \mathrm{h}$. Most of the system sub-components, including the CHP engine, combustor and heat exchangers, are commercially available so could be procured 'off-the-shelf' at the desired capacities from the suppliers. As the intermediate pyrolysis system is novel, it would require fabrication by contractors. When considering scale-up, account must be taken of the upper limit of reactor capacity for a single unit. For the particular reactor used here, this limit exists because the current design of the reactor is externally heated at the reactor skin (using the heat form char combustion in an external heating jacket, as shown in Figure 2). The heat transfer rate for a given delta-T is proportional to the reactor surface area, whereas the heat demand for pyrolysis is proportional to the reactor volume as more feedstock can be processed. The ratio of surface area to volume decreases with the reactor scale. When the reactor exceeds a certain scale, the reactor may be unable to transfer sufficient internal heat for the pyrolysis reaction. $200 \mathrm{~kg} / \mathrm{h}$, therefore, has been assumed for the upper limit of a single pyrolysis reactor. For Pyro-CHP system exceeding this capacity, multiple reactor units are used.

For the products from the Pyro-CHP system, it is assumed that all of the pyrolysis oil produced in the pyrolysis system is used to generate electrical power and heat, which will be sold through the grid to a utility company and through a local district heating network in the form of hot water, respectively. The char product will be sold as charcoal for fuel applications or as bio-char for soil improvement. There are electrical power distribution and transmission losses of approximately $2 \%$ and heat transmission losses of approximately 10\% [30,31]. However, within the economic calculations, these losses are not deducted from the total saleable units as this cost is normally passed on to the consumers. It is also assumed that the customers are willing and able to purchase all of the products (including all the electricity and heat produced) when they are available in the market. The CHP scheme satisfies the quality assessment defined by DECC (recognised as Good

Quality CHP) [32]. The engine fuels used satisfy the criteria of the UK Renewable Obligation (RO) and Renewable Heat Incentive (RHI) and fully qualify for the incentive payments.

\subsection{Capital cost}

The baseline equipment costs of the Pyro-CHP system components used in this work are derived 
either from the cost estimates for the equipment available at the Aston University demonstration plant (i.e. the $100 \mathrm{~kg} / \mathrm{h}$ intermediate pyrolysis reactor, $400 \mathrm{~kW} \mathrm{CHP}$ engine and $30 \mathrm{~kg} / \mathrm{h}$ char combustor), or from the cost estimates provided by commercial suppliers or manufacturers (i.e. the shell and tube heat exchangers) [26]. All the equipment cost data collected prior to 2014 has been adjusted to 2014GBP by using Chemical Engineering Plant Cost Index (CEPCI), namely $2010=550.8 ; 2011=585.7 ; 2012=584.6 ; 2013=567.3 ; 2014=576.1[33]$. When evaluating the scaled up systems, the costs for the system components in different capacities are adjusted by applying the well-known six-tenths rules quoted by Sinnot [29] and SKM Enviros [34].

The method used for calculating the total capital requirement for an energy plant using pyrolysis technology was developed by Bridgwater et al [17] and Brammer [35] in the early 2000s. Total plant cost (TPC) is the measurement of the project capital cost, which is the total amount of capital required to finance the whole system to the point at which it is ready to operate. The calculation of TPC starts with the summation of the equipment cost (EC), which is the cost of purchasing brand new equipment of the major components in the subsystem, delivered to the plant gate. Increments are then included for erection, instrumentation, piping and ducting, associated electrical equipment, structures and buildings, civil works and laggings, to give a direct plant cost (DPC). Costs of engineering design and management overheads are then added to give an installed plant cost (IPC), and finally commissioning costs, contractor's fees, interest during construction and a contingency element are added to give the TPC. These increments are less specific to system modules, being usually approximated as fixed percentages of direct plant cost. According to a study for a similar system [36], the TPC is chosen to be 1.69 times the DPC, which is the production of the EC and a number of multiplication factors. The breakdown of TPC for each system is shown in Figure 3 and the calculated values are presented later in Table 2 (Section 3.3.4). 


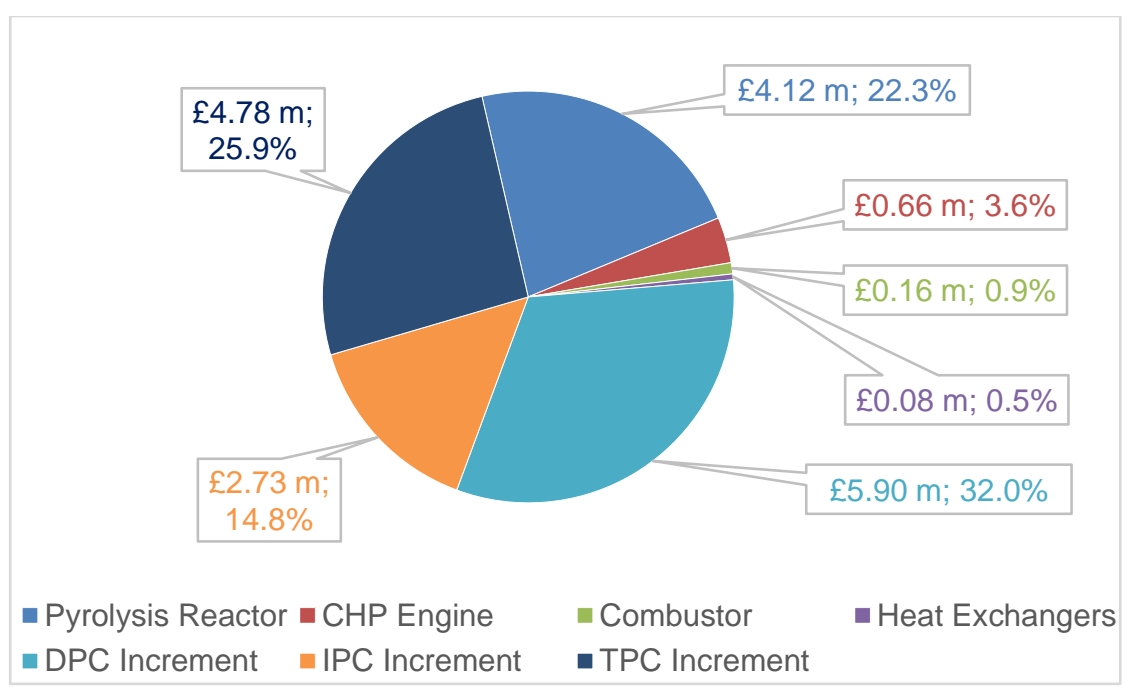

Figure 3: Breakdown of TPC of the Pyro-CHP system at different scales (1000 kg/h System)

The "learning effect" describes the progressive capital cost reduction which is seen as installations of a new technology are replicated. The learning effect model applied here has been used extensively in industry as a tool for production planning and cost forecasting, and is based on a fixed percentage reduction in cost per doubling of cumulative production [17,37]. Since the intermediate pyrolysis system is a relatively new technology, a future cost of the pyrolysis unit with learning effect applied is calculated as well as the current cost.

The annual cost of capital (ACC) is the annual levelised repayment over the lifetime of the project, and assumes that the full capital amount (TPC) is loaned at the start of the project at a specified real interest rate. The ACC is calculated as follows:

$$
A C C=T P C \frac{i(1+i)^{n}}{(1+i)^{n}-1}
$$

where $n$ is the project lifetime in years and $i$ is the real interest rate for the capital loan. Although UK economy interest rates are set by the central bank at $<2 \%$ since 2008 there is significant cost in securing finance and the proposed project would carry some perceived technological and execution risk. Therefore, work considering the similar economic studies and the risk on capital investment an interest rate of $15 \%$ has been used in the modelling [38-41]. 


\subsection{Operating costs}

Plant operating costs are split into consumables, maintenance costs, utility costs and labour costs. These are the ongoing costs incurred from plant operation and are represented as annual costs.

\subsubsection{Consumables}

The price of wood pellets varies with the quantity ordered. The delivery charges are generally applied per delivery rather than per tonne, so the price will be lower for a larger quantity delivery. The price of wood pellets used here is estimated to be $£ 230$ per tonne according to a quotation provided by a UK wood pellets supplier [42].

A blend of pyrolysis oil and biodiesel (50/50 volumetric ratio) is used as the CHP engine fuel. Following discussions with industry, the price of used cooking oil (UCO) derived biodiesel is estimated to be $£ 0.69$ per litre (excluding VAT and UK road fuel duty) [43].

\subsubsection{Maintenance and overheads}

Annual maintenance costs and overheads costs (including insurance, rent, taxes etc.) are calculated as a percentage of TPC per annum. The present study uses $2.5 \%$ of TPC for plant maintenance and $2.0 \%$ of TPC for plant overheads costs in line with previous comparable work [17].

\subsubsection{Utility cost}

Utility cost includes electricity and cooling water usage for the pyrolysis and CHP system. In this work, the electricity consumed for general usage and the parasitic load of the plant is imported from the grid, as this will ensure stable operation of the plant. This is a lack of relevant literature information for the intermediate pyrolysis and engine plant. However, according to Bridgwater [17], electricity consumption for a fast pyrolysis and engine plant is estimated to be $36.8 \mathrm{kWh}$ per tonne of wood feedstock. Adopting this data to the present work is reasonable when considering the fact that both processes involve similar arrangement and the pyrolysis reactors process similar feedstock and provide heating to the same range of temperature. The average electricity price for non-domestic consumers is 10.01 pence per $\mathrm{kWh}$ (2014 rate) [44]. The water utility cost includes 
the cost of water usage (a fixed amount plus metre reading) and surcharges for sewerage and effluent treatment. The water consumption is estimated to be $17 \mathrm{~m}^{3}$ per tonne of wood feedstock [17]. According to relevant information from a British water company, an approximate water cost of $£ 2.80 / \mathrm{m}^{3}$ is used here [45]. This is an averaged value combining the costs of water utility and process waste water disposal.

\subsubsection{Labour cost}

There is no established model for staffing levels on pyrolysis and CHP plant. It is assumed that the staffing level of a plant is related to the plant scale. All sizes of the plant would require a control room and, at least, two plant attendants for the pyrolysis and CHP units respectively while they are operating. The staff requirement is divided into a day team and a shift team. The day team includes the plant manager and technician, and the number of staff required depends on the load of management work and any maintenance and support contracts that are in place. The shift team members include the plant operators and their supervisor, and the number of staff required depends on the number of equipment items that need to be operated.

A weekly wage of $£ 725.7$ for each employee is used here assuming 52 weeks per year. This weekly rate is calculated based on the 2013 UK average weekly wage (£715) for employees in the electricity industry [46] and adjusted by an average annual salary inflation rate of $1.5 \%$ from 2009 to 2015 [47]. This net staffing cost is then increased by $23.7 \%$ to cover employer's national insurance (11\%), pension contribution (5\%), and training (2.7\%) and administration charges (5\%) [36]. This results in an annual labour cost of $£ 46.68 \mathrm{k}$ per employee. Table 1 shows the estimated labour requirement and costs for the Pyro-CHP plants.

Table 1. Staffing level and cost

\begin{tabular}{|c|c|c|c|c|c|c|}
\hline \multirow{2}{*}{$\begin{array}{c}\text { Capacity } \\
(\mathrm{kg} / \mathrm{h})\end{array}$} & \multicolumn{2}{|c|}{ Day Team } & \multicolumn{2}{|c|}{ Shift Team } & \multirow{2}{*}{$\begin{array}{l}\text { Total } \\
\text { (head) }\end{array}$} & \multirow{2}{*}{$\begin{array}{c}\text { Labour } \\
\text { Costs (£) }\end{array}$} \\
\hline & Manager & Technician & Supervisor & Operator & & \\
\hline 200 & 1 & 0.5 & 1 & 2 & 10.5 & 490,139 \\
\hline 600 & 1 & 1 & 1 & 3 & 14 & 653,519 \\
\hline 1000 & 1 & 1.5 & 1 & 3 & 14.5 & 676,859 \\
\hline
\end{tabular}

Considering all the aspects discussed above, the project costs are summarised in Table 2. 
Table 2. Project costs

\begin{tabular}{|c|c|c|c|c|}
\hline & & $200 \mathrm{~kg} / \mathrm{h}$ Plant & $600 \mathrm{~kg} / \mathrm{h}$ Plant & $1000 \mathrm{~kg} / \mathrm{h}$ Plant \\
\hline Total Capital Cost (TPC) & $£$ & $4,372,767$ & $11,481,049$ & $18,434,568$ \\
\hline Annual Costs of Capital (ACC) & $£ / a$ & 698,600 & $1,834,229$ & $2,945,134$ \\
\hline Operating Cost & $\mathfrak{f} / \mathbf{a}$ & $1,522,345$ & $3,664,164$ & $5,657,899$ \\
\hline Feedstock (wood) & $£ / a$ & 368,000 & $1,104,000$ & $1,840,000$ \\
\hline Biodiesel & $£ / a$ & 382,320 & $1,148,040$ & $1,912,680$ \\
\hline Maintenance & $£ / a$ & 85,111 & 241,958 & 398,805 \\
\hline Overhead & $£ / a$ & 87,455 & 229,621 & 368,691 \\
\hline Utility & $£ / a$ & 80,210 & 227,254 & 374,298 \\
\hline Labour & $£ / a$ & 490,139 & 653,519 & 676,859 \\
\hline
\end{tabular}

\subsection{Product sales}

\subsubsection{Levelised electricity cost (LEC)}

The LEC is the minimum product selling price that covers the costs of production. It is often cited as a convenient measure of the overall competitiveness of different energy generating technologies by the DECC and IEA [48]. The Pyro-CHP system investigated in this work produces electricity, heat and char. The calculation of LEC assumes that the other two products have been purchased by the customers at the market price and the associated subsidies have been paid.

The $\mathrm{LEC}_{\text {elec }}$ is calculated as:

$$
L E C_{\text {elec. }}=\frac{(A C C+O P)-S_{\text {heat }}-S_{\text {char }}}{Q_{\text {elec. }}}-Q_{\text {elec. }} \times R_{\text {elec } .}
$$

where, $A C C$ is the annual cost of capital, in $£ / a ; O P$ is the annual operating cost, in $£ / a ; Q$ is quantity of energy product produced, in $\mathrm{kWh} / \mathrm{a} ; S$ is the annual sale of the product, in $£ / \mathrm{a} ; R$ is the rate of subsidy, in $£ / \mathrm{kWh}$, i.e. ROC trade value for electricity.

\subsubsection{Energy product prices}

In this work, the wholesale electricity selling price (to the distribution grid) is taken as $£ 0.055 / \mathrm{kWh}$. The selling price for heat is taken to be $0.0349 / \mathrm{kWh}$. This is based on the equivalent price for heat generation from natural gas using the 2014 average gas price $(0.297 / \mathrm{kWh})$ and a 
boiler efficiency of $85 \%$ [44]. District heating applications are becoming increasingly common in the UK, the model being used is that new developments with either a thermal demand or generation capacity should have pipework and flanges available to allow them to connect to either existing or future district heat networks. This approach reduces the capital burden on project developers whilst keeping new developments district heat ready for such a time when the business case for connection is viable. This situation is beginning to emerge in major UK conurbations. When considering that economic case the comparison is always against 'conventional' natural gas given that so much of the UK is connected to the gas grid (90\%) [49]. The surplus char product (remainders after taking out the proportion of char used in combustor) can be utilised either as charcoal for solid fuel applications or as bio-char for soil application [50]. Previous work on intermediate pyrolysis of wood pellets has presented that the char product contains over $75 \%$ carbon and has a HHV of over $30 \mathrm{MJ} / \mathrm{kg}$, which compare well to typical sub-bituminous class coal and charcoal from wood torrefaction [21,51]. From consideration of the average market price for UK hardwood charcoal in $2014, £ 0.8 / \mathrm{kg}$ (or $£ 0.096 / \mathrm{kWh}$ ) is used as the wholesale price of char for fuel. The scenario for selling char product as bio-char is not analysed in the base case study but discussed in the sensitive analysis.

\subsubsection{Renewable incentives}

After the RO Banding Consultation in 2012, DECC (Department of Energy \& Climate Change) and Ofgem (Office of Gas and Electricity Markets, the administrator of the RO) finally confirmed that, effective from April 2013, the electrical power produced by the pyrolysis of biomass will be supported under the RO ACT Band (Advanced Conversion Technologies, i.e. pyrolysis and gasification). This meant that the pyrolysis of biomass was eligible for the maximum level of support under the scheme: 2 ROCs/MWh of eligible renewable electricity generated [52,53]. The electrical power produced from biodiesel is currently categorised as dedicated biomass with CHP and also attracts 2 ROCs/MWh [53,54]. As a Pyro-CHP system, as proposed, would fall partially under these two banding mechanisms within the RO scheme it would require a bespoke assessment by Ofgem before being accredited.

Typical biodiesel produced from transesterification of vegetable oil requires substantial amounts of methanol, normally derived from natural gas by steam reforming and associated reactions. This 
type of biodiesel is therefore not $100 \%$ renewable and as a result was not formerly eligible for RO accreditation [55]. However, in 2013, the government revised the policy and introduced the Fuel Measurement and Sampling (FMS) method for determination of fossil fuel content in biodiesel. If the energy share of the fossil part of the fuel is less than $10 \%$, the transesterified biodiesel is eligible under the RO [56].

It is assumed that the biodiesel used in this study is manufactured from UCO (over $80 \%$ of UK biodiesel is produced from waste raw material [57]) and conventional methanol through the transesterification process. Assuming the UCO was soybean-derived oil, an official FMS procedure study reports that this type of biodiesel contains an average mass share of $10.64 \%$ methoxy group (fossil-derived part), which equates to an energy share of $3.92 \%$ of the total biodiesel energy content [56]. In the present work, the biodiesel is $50 \mathrm{vol} \%$ blended with pyrolysis oil. This volumetric ratio is equivalent to a mass share of $45.04 \%$ of biodiesel in wood oil blends as a result of different densities. This consequently leads to a fossil energy share of $2.25 \%$ of the total energy content in wood oil blends. These values are much lower than the maximum allowable fossil composition in the feedstock (10\%) and, therefore, the proposed systems are fully eligible under the RO. The proportions of pyrolysis oil and biodiesel (including renewable and fossil part) in terms of volume, mass and energy are presented in Table 3.

Table 3. Volume, mass and energy shares of the CHP engine fuel

\begin{tabular}{|l|c|c|c|}
\hline & Volume Share & Mass Share & Energy Share \\
\hline Pyrolysis Oil & $50.00 \%$ & $54.96 \%$ & $42.66 \%$ \\
\hline Biodiesel (total) & $50.00 \%$ & $45.04 \%$ & $57.34 \%$ \\
\hline Biodiesel (renewable) & -- & $40.25 \%$ & $55.10 \%$ \\
\hline Biodiesel (fossil) & -- & $4.79 \%$ & $2.25 \%$ \\
\hline
\end{tabular}

In 2014 , there was a total number of $1,121,242$ ROCs traded with an average value of $£ 41.83$ per ROC [58]. The renewable energy consumer is also entitled to an exemption from the Climate Change Levy on their electricity bill, which was $£ 0.0054$ per kilowatt electricity consumed $[59,60]$.

In the RHI, there is currently no clear definition for renewable heat produced from biomass pyrolysis CHP systems, especially with regard to the blended biodiesel fraction. As it currently 
stands within the scheme bio-liquids are exempt but pyrolysis is not and falls under the biogas tariff. This remains a grey area in the policy largely due to the lack of commercial pyrolysis plants operating within the UK. In this work, it is considered that only the proportion of heat generated from pyrolysis oil (on the energy basis) is supported by the non-domestic RHI scheme in the biogas combustion band. In 2014, the average support level for the newly accredited system is 6.06 pence per $\mathrm{kWh}_{\text {th }}$ for the heat output capacity in the range of 200-600 $\mathrm{kWh}$ th, and 2.27 pence per $\mathrm{kWh}_{\text {th }}$ for heat output capacity over $600 \mathrm{kWhth}$ [61]. These rates are then discounted by $42.66 \%$, considering the energy content of the pyrolysis oil in the engine fuel (shown in Table 3). Table 4 presents the product selling prices and their incentive rates (2014 rates) used in this work.

Table 4. Energy price and incentive rates

\begin{tabular}{|c|c|c|}
\hline \multicolumn{3}{|l|}{ Electricity } \\
\hline $\mathrm{ROC}^{*}$ & ROC/MWhe & 2 \\
\hline ROC Value & $£ / \mathrm{ROC}$ & 41.83 \\
\hline Elec. Price & $£ /$ kWhe & 0.0550 \\
\hline \multicolumn{3}{|l|}{ Heat } \\
\hline $\mathrm{RHI}^{* *}$ & RHI/MWhth & 0.4266 \\
\hline RHI Value (200-600 kWhth) & $£ /$ kWhth & 0.0606 \\
\hline RHI Value (<600 kWhth) & $£ /$ kWhth & 0.0227 \\
\hline Heat Price & $£ /$ kWhth & 0.0349 \\
\hline \multicolumn{3}{|l|}{ Char } \\
\hline Char Price & $£ / \mathrm{kg}$ & 0.8000 \\
\hline Char Price & $£ / k W h$ & 0.0957 \\
\hline
\end{tabular}

*This ROC is the combined ROC for electrical power generated from both pyrolysis oil and biodiesel. Both fuels entitle 2 ROC/MWhe. **This RHI is the combined RHI for heat generated from both pyrolysis oil and biodiesel. Only the pyrolysis oil entitles $1 \mathrm{RHI} / \mathrm{MWhth}$. The value shown has been discounted by the energy content of the energy content of the pyrolysis oil in the fuel blend.

\section{Environmental life-cycle analysis model}

In this section, an environmental life-cycle analysis of the intermediate pyrolysis CHP system is calculated and presented.

The GHG emissions generated from the energy system during the life-cycle can be classified as direct and indirect GHG emissions. The direct GHG emissions are those from the combustion of 
the products of the liquid fuels in the engine. However, it is worth noting that most of the carbon in the fuel is from the biomass feedstock (the "neutral carbon") so its gaseous emission is not considered as additional GHG emission to the atmosphere. Only those emissions from combustion of the fossil part of the biodiesel (Section 3.4.3) are counted as direct GHG emissions. The indirect GHG emissions are the total emissions from any other source. These include the emissions from the material production chain when the wood feedstock and biodiesel are produced (upstream emissions), transported and distributed, as well as emissions, which occur during plant construction, commissioning, operation and decommissioning.

\subsection{System Boundary}

The system boundary covers the GHG emissions of production of the biomass feedstock and biodiesel fuel, transportations of feedstock, biodiesel and surplus char (from pyrolysis), production of power, heat and biochar, and application of surplus char. GHG discussed in this work includes $\mathrm{CO}_{2}, \mathrm{CH}_{4}$ and $\mathrm{N}_{2} \mathrm{O}$. For simplicity of reporting and discussing, the environmental effects of $\mathrm{CH}_{4}$ and $\mathrm{N}_{2} \mathrm{O}$ are converted to a $\mathrm{CO}_{2}$ equivalent measure based on applied factors for 100-year global warning potential of 25 for $\mathrm{CH}_{4}$ and 298 for $\mathrm{N}_{2} \mathrm{O}$, as recommended by IPCC [62]. The total GHG emissions are then reported as $\mathrm{CO}_{2}$ equivalent $\left(\mathrm{CO}_{2} \mathrm{e}\right)$. The $\mathrm{GHG}$ life-cycle emissions are evaluated based on the amount of energy generated (heat and power) from the system. Hence, one kilowatthour $(\mathrm{kWh})$ is selected as the functional unit for reporting GHG emissions.

The calculation of life-cycle GHG emissions is expressed as:

$$
G H G=\frac{E_{U}+E_{P}+E_{f}}{Q}
$$

where $E_{u}, E_{p}$, and $E_{f}$ are the upstream emissions, plant emissions and direct fuel emissions respectively in $\mathrm{kgCO}_{2} \mathrm{e} / \mathrm{a}$, and $Q$ is the quantity of energy product produced in $\mathrm{kWh} / \mathrm{a}$.

\subsection{Upstream}

It is assumed that the wood pellet feedstock for the Pyro-CHP system is produced by a wood pellet 
mill at a forest in Northumberland. The life cycle of wood pellets production covers the raw wood material processing (including forest harvesting, forest road construction and maintenance, and forest renewal) and pellets production (including hammer mill crushing, grinding, drying, pelletising and cooling), and associated transportation. In the case of forest wood, land use change on GHG emissions is not considered. Zhang et al $[63,64]$ estimated that the raw wood material processing produces approximately $0.04241 \mathrm{kgCO}_{2} \mathrm{e}$ per $\mathrm{kg}$ of wood pellets produced, and pellet production produces approximately $0.03953 \mathrm{kgCO}_{2} \mathrm{e}$ per $\mathrm{kg}$ of wood pellets produced. This in total gives life-cycle $\mathrm{GHG}$ emissions of $0.08194 \mathrm{kgCO}_{2}$ e per $\mathrm{kg}$ wood pellets produced.

Industrial production of biodiesel involves using long chain fatty acid (generally vegetable oil or animal fat) and methanol (generally from fossil sources). The UK's Renewable Transport Fuels Obligation (RTFO) reported the carbon intensity for producing biodiesel from UCO is 14 $\mathrm{gCO}_{2} \mathrm{e} / \mathrm{MJ}$. This is equivalent to $\mathrm{GHG}$ emissions of $0.556 \mathrm{kgCO}_{2} \mathrm{e}$ per $\mathrm{kg}$ biodiesel produced, considering the heating value of $39.7 \mathrm{MJ} / \mathrm{kg}$ for biodiesel used in this work.

\subsection{Material transport and distribution}

Transportation of the wood pellets includes transportation of the harvested wood material from the forest to the pellet mill and delivery of the product from the pellet mill to the Pyro-CHP plant. In this work, it is assumed that the wood pellets are produced in Northumberland and delivered to the central Midland area for consumption. The transportation distance is estimated to be $420 \mathrm{~km}$. It is also assumed that the biodiesel used in this work is produced in Teesside and distributed to same central Midland area [65]. The transportation distance is estimated to be $280 \mathrm{~km}$. Char product produced at the Pyro-CHP plant is distributed either to a local co-firing power plant for power production or to a farmland for soil application. It is assumed the transportation distance is 150 $\mathrm{km}$. For land transportation, an average GHG emission of $0.5319 \mathrm{kgCO}_{2} \mathrm{e}$ per tkm (tonnekilometre, the transportation of one-tonne material over one kilometre) for diesel vans is used, as retrieved by UK Defra's GHG Conversion Factors Repository in 2013 [66,67].

\subsection{Plant construction and operation}

There is a lack of dedicated data for GHG emissions from the direct construction, commissioning 
and decommissioning of a pyrolysis-based energy plant. However, Hondo [68] examined a range of different conventional fossil-fuelled generation technologies and concluded that this part of the emissions accounts for $0.3-0.5 \%$ of the total plant life-cycle GHG emissions. In the present work, $0.4 \%$ is used, assuming all the energy used during this stage is derived from a fossil source. The GHG emissions from the plant operation include those from all on-site operations powered by imported electricity. The GHG emissions from electricity use are taken to be $0.394 \mathrm{kgCO}_{2} \mathrm{e}$ per $\mathrm{kWh}$, the UK average value for electricity generation reported by DECC [69]. They also include those from water usage, taken to be $0.678 \mathrm{kgCO}_{2} \mathrm{e}$ per tonne of water used (inclusive of water supply and waste disposal), the average value reported by two UK major water suppliers [70,71].

\subsection{System GHG emissions}

The total GHG emissions of the Pyro-CHP system include the GHG emitted from the combustion of pyrolysis gases and char in the combustor and from the combustion of pyrolysis oil and biodiesel blends in the CHP engine. Assuming all fuels input to the system are fully and completely combusted and the exhaust gases are emitted in the form of $\mathrm{CO}_{2}$, the total $\mathrm{CO}_{2}$ emission is calculated from the Aspen Plus flowsheet. The results are shown in Table 5.

However, as discussed in Section 3.4.3, there is a fossil-derived component existing in the biodiesel used. This part accounts for an energy share of $2.25 \%$ and a mass share of $4.79 \%$ in the whole pyrolysis oil-biodiesel blend. This factor will be applied to the amount of exhaust gas emission and this part of $\mathrm{CO}_{2}$ emission will be accounted as non-renewable emission.

\subsection{Application of char product}

The majority of char produced by the Pyro-CHP system will be surplus char product (after deducting the amount combusted in the system). For soil applications, it is widely accepted that $70 \%$ of the carbon in the bio-char is resistant to microbial degradation and therefore highly stable in soil and will not be emitted back to the atmosphere (the remainder are ash, oxides and residual degradable carbon, i.e. pyrolysis oil residue) [72]. Considering the mass ratio of carbon and $\mathrm{CO}_{2}$, a factor of 3.67 is used here for converting the mass of stable carbon to that of $\mathrm{CO}_{2}$. Previous work has also shown that utilising bio-char in farmland applications can also significantly reduce the 
$\mathrm{N}_{2} \mathrm{O}$ emission resulting from using nitrogen fertiliser - a reduction of $50 \%$ of $\mathrm{N}_{2} \mathrm{O}$ per unit farmland area is commonly used in research [73-76]. This is equivalent to a rate of $0.394 \mathrm{~kg} \mathrm{~N}_{2} \mathrm{O}$ emission avoided per each tonne of biochar used in farmland [74]. Using surplus char product as a co-firing fuel for power generation is also considered in this work, as this has been a popular approach to reduce fossil carbon and sulphur emissions in power generation [77]. Wood derived char from intermediate pyrolysis contains $75.6 \%$ carbon and has a heating value of $30.1 \mathrm{MJ} / \mathrm{kg}$ [21]. Taking $35.7 \%$ (of the energy input) as the average thermal efficiency of coal fired plants in the UK [69], the amount of electricity generated by surplus char per year can be calculated.

\section{$5 \quad$ Results and Discussion}

\subsection{Mass and energy balances and system efficiencies}

Table 5 presents the feedstock characteristics and the results of the system energy balance, engine electrical efficiency and CHP efficiency (combined electricity and heat output divided by the summation of the pyrolysis oil and biodiesel energy input) and overall Pyro-CHP system CHP efficiency (combined electricity and heat output divided by the summation of pellet feedstock and biodiesel energy input). These data are utilised as the baseline information for the economic analysis.

Table 5. Mass and energy balances and efficiencies for the integrated Pyro-CHP system

\begin{tabular}{|c|c|c|c|c|c|}
\hline \multicolumn{6}{|c|}{ FEEDSTOCK } \\
\hline \multicolumn{2}{|l|}{ Throughput } & $\mathrm{kg} / \mathrm{h}$ & 200 & 600 & 1000 \\
\hline \multicolumn{2}{|l|}{ Moisture } & wt. \% & \multicolumn{3}{|c|}{8.0} \\
\hline \multicolumn{2}{|c|}{ Energy Content (HHV) } & $\mathrm{MJ} / \mathrm{kg}$ & \multicolumn{3}{|c|}{18.2} \\
\hline \multicolumn{2}{|l|}{ Particle size } & $\mathrm{mm}$ & \multicolumn{3}{|c|}{$5-30$} \\
\hline \multirow{6}{*}{$\begin{array}{l}\text { Feedstock } \\
\text { Composition }\end{array}$} & Carbon & wt. $\%$ db* & \multicolumn{3}{|c|}{51.1} \\
\hline & Hydrogen & wt. $\% \mathrm{db}$ & \multicolumn{3}{|c|}{5.7} \\
\hline & Nitrogen & wt. $\% \mathrm{db}$ & \multicolumn{3}{|c|}{0.4} \\
\hline & Oxygen & wt. $\% \mathrm{db}$ & \multicolumn{3}{|c|}{39.2} \\
\hline & Sulphur & wt. $\% \mathrm{db}$ & \multicolumn{3}{|c|}{0.1} \\
\hline & Ash & wt. $\% \mathrm{db}$ & \multicolumn{3}{|c|}{3.4} \\
\hline \multicolumn{2}{|c|}{ Pyrolysis Temperature } & ${ }^{\circ} \mathrm{C}$ & \multicolumn{3}{|c|}{450} \\
\hline \multicolumn{6}{|c|}{ MASS BALANCE } \\
\hline Yields & Oil & $\mathrm{kg} / \mathrm{h}$ & 43.2 & 129.6 & 216.0 \\
\hline
\end{tabular}




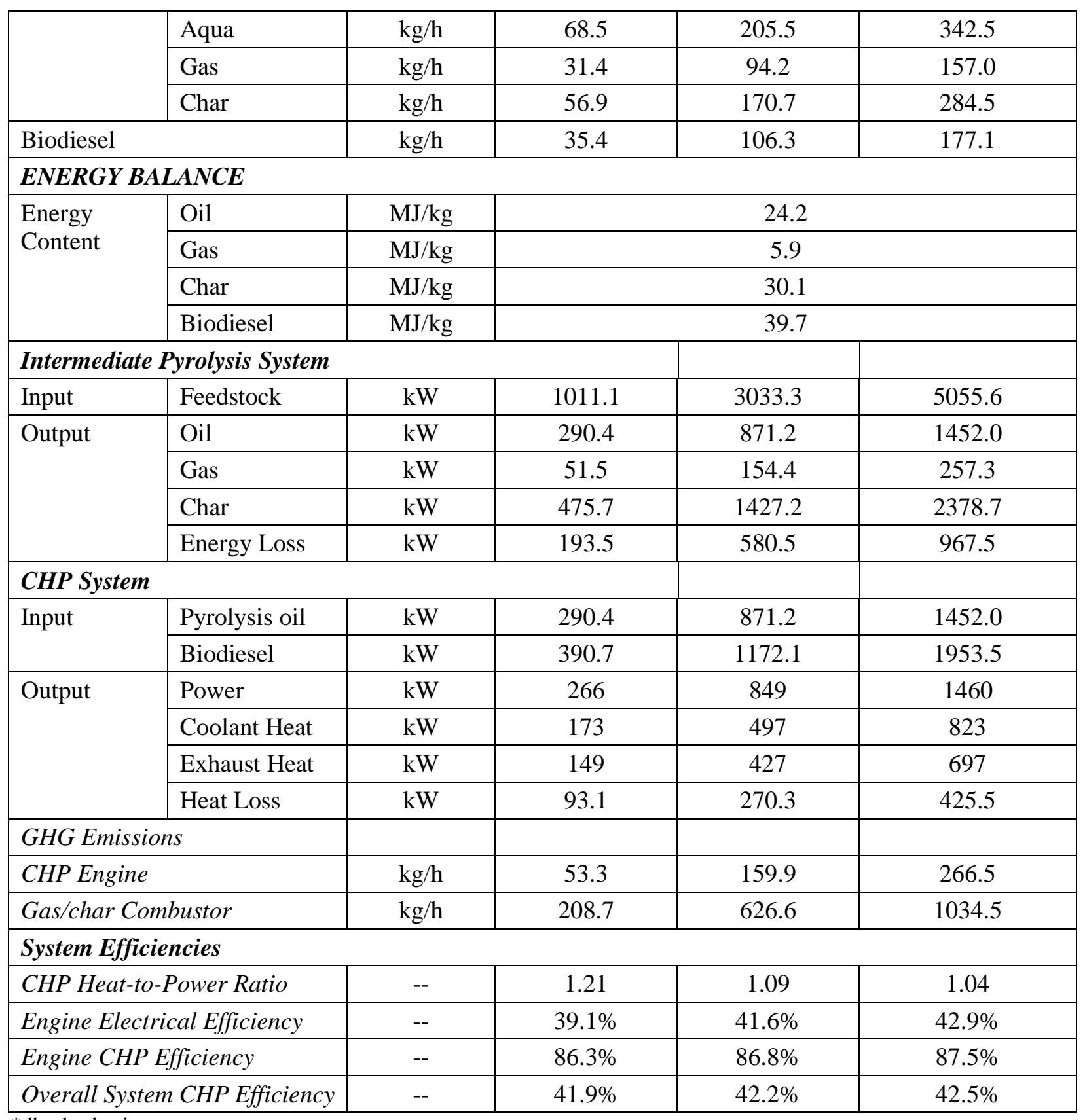

*db: dry basis

The yields of pyrolysis oil, gas and char from the intermediate pyrolysis reactor are 21.6, 15.7 and 28.5 wt.\% respectively. The remainder is the aqueous fraction of pyrolysis liquid, which is considered as a waste in this work. The electrical power outputs for the 200, 600 and $1000 \mathrm{~kg} / \mathrm{h}$ system are 266,849 and $1460 \mathrm{~kW}$, which is equivalent to engine electrical efficiencies of $39.1 \%$, $41.6 \%$ and $42.9 \%$ respectively. The results show a slight increase in the electrical efficiency with the increase of engine capacity due to the scale effect (see Section 2.2). These values obtained can 
be validated by the work carried out by Lantz [78]. Both the engine CHP electrical efficiency and overall system CHP efficiency are slightly increased with the increase of system scale, although the difference is within $1 \%$. By comparing the system efficiencies, it can be seen that most of the energy losses occur during the pyrolysis stage, where pyrolysis gas and a portion of char product are burnt for supplying heat to the pyrolysis reactor, hot pyrolysis vapour is condensed to form liquid and hot char is cooled in the collecting vessel. In real industrial application, these parts should be carefully designed in order to gain an optimised overall system efficiency.

\subsection{Economic evaluation}

\subsubsection{Levelised electricity cost}

Figure 4 shows the calculated LECs and the breakdown of contributions for the current Pyro-CHP plants. Bars with positive values are the direct cost incurred in the capital investment and plant operation while bars with negative values are the sales revenues for the heat and surplus char, as well as incentive rates paid for the renewable electricity and heat. The net electricity LEC values for 200,600 and $1000 \mathrm{~kg} / \mathrm{h}$ plant are $£ 0.656, £ 0.461$ and $£ 0.396 / \mathrm{kWhe}$.

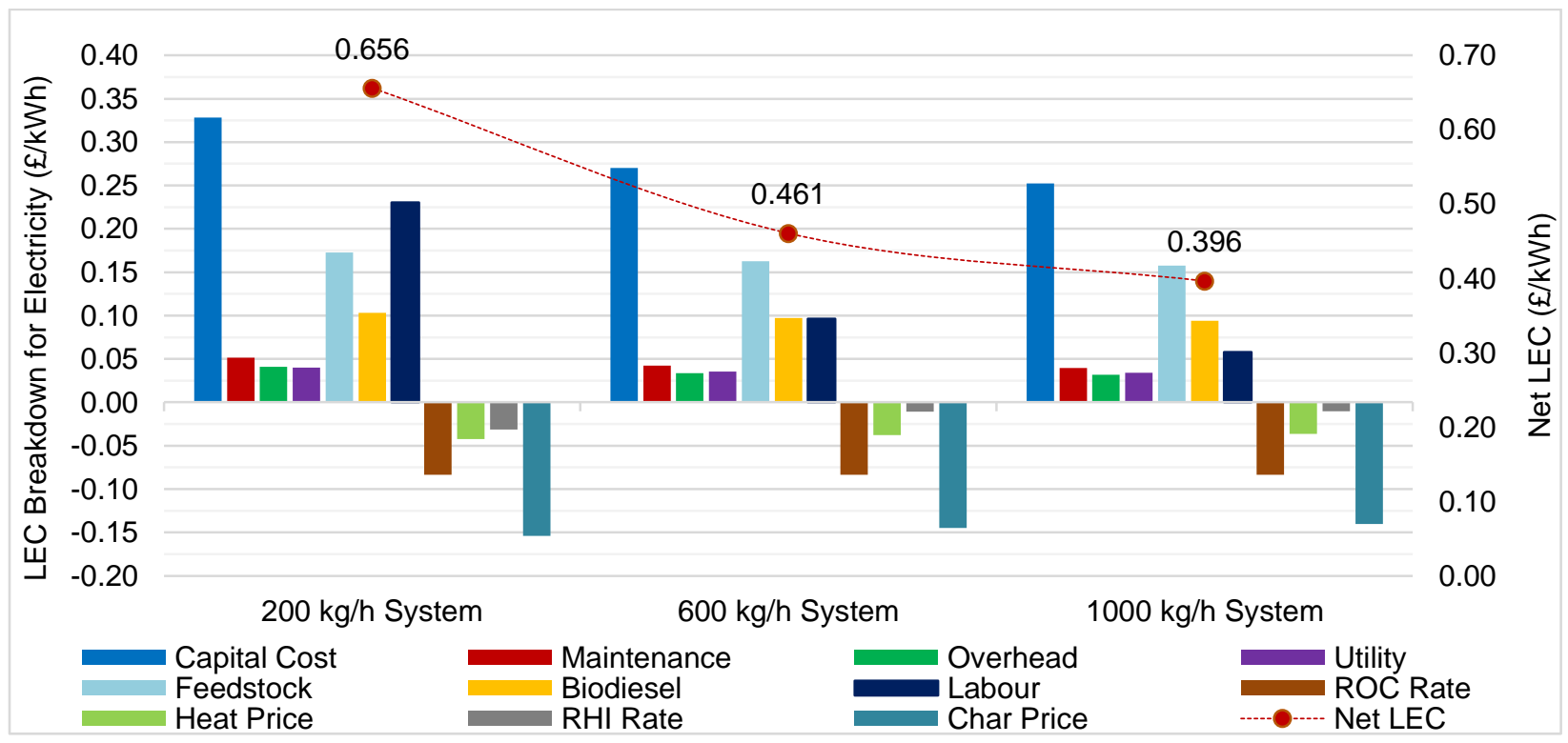

Figure 4. Breakdown of LEC

Overall, the most significant contributing component to the LEC is the capital investment, but its percentage of contribution reduces with increasing capacity due to the economy of scale [79]. As 
seen in Section 3.2, the pyrolysis reactor accounts for the highest proportion of the total equipment cost; however, this element does not contribute to the economy of scale because there are multiple pyrolysis units required to handle additional throughput for the plant over $200 \mathrm{~kg} / \mathrm{h}$ (see Section 3.2). Although multiple reactors within the same plant can share some auxiliary equipment and the operation/maintenance requirement generally has less than a linear increase, the capital cost savings are modest. In industrial production, if larger pyrolysis reactor can be manufactured, the capital cost for high capacity plant can be significantly reduced. The costs of the feedstock and biodiesel remain nearly constant, due to a nearly linear relationship between material requirement and electricity produced. However, the tendency shows the feedstock cost has strong potential to eventually surpass the capital cost and become the most significant factor of the LEC at a larger scale plant. The contribution of labour cost is higher than that of feedstock cost in the smaller scale plant $(200 \mathrm{~kg} / \mathrm{h})$ but falls noticeably in the larger plants. This is because fewer operators per kilowatt-hour electricity are required in the larger plants. Operation, management and utilities represent the smallest contributions, and there are small reductions seen when the plant capacity is increased. In terms of product sales revenue, the char sales clearly contribute the most. It is interesting to note that the income from char can almost cover the feedstock cost in all plants, and the difference between them reduces with increase in plant capacity. The ROC rate remains constant, but the return rate for heat under the RHI is reduced with the increase of plant capacity due to the slight reduction in CHP heat-to-power ratio (shown in Table 5). The overall results show that the larger plants have the advantage of lower LEC due to gradually reduced costs (at high capacity plants) but relatively constant incentive payments.

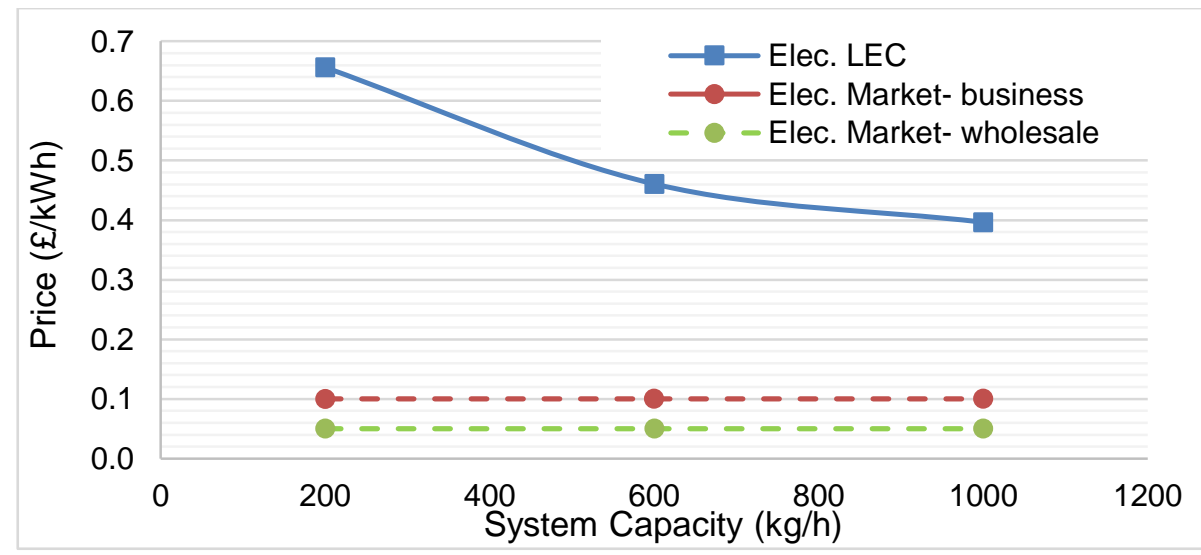

Figure 5. Comparison of calculated LEC and UK electricity market values 
Figure 5 shows the calculated current LEC values for different plant capacities and highlights the economy of scale effect. Comparing the LEC values for the different plant scales, scaling up by 3 and 5 times has resulted in a $29.8 \%$ and a $39.6 \%$ cost reduction (from $£ 0.656 / \mathrm{kWh}$ to $£ 0.461$ and $£ 0.396 / \mathrm{kWh}$ ), respectively. Comparison of current product LECs with their market values (Figure 5) shows that the Pyro-CHP system does not currently produce competitive energy products. The UK wholesale electricity price is approximately $£ 0.05 / \mathrm{kWh}$ for power sold into the electricity grid, the scheme modelled is therefore far from economic in this situation. The typical purchase price for a large electricity user is around $£ 0.1 / \mathrm{kWh}$ [44]. The calculated LEC of $£ 0.396-0.656 / \mathrm{kWh}$ for the Pyro-CHP scheme shows it is a poor investment for on-site generation compared to purchasing grid electricity.

\subsubsection{Sensitivity analysis}

In addition to the base case analysis, the sensitivities of 14 single variable contributors to the LEC, including capital cost, operating cost, product productivities and their sales revenue, are analysed in turn by varying $\pm 20 \%$ of their baseline data on $1000 \mathrm{~kg} / \mathrm{h}$ system. This analysis can determine how different values of the cost factors impact the LEC and consequently to help the project developer to identify the strategy on reducing LEC. The results are shown in Figure 6.

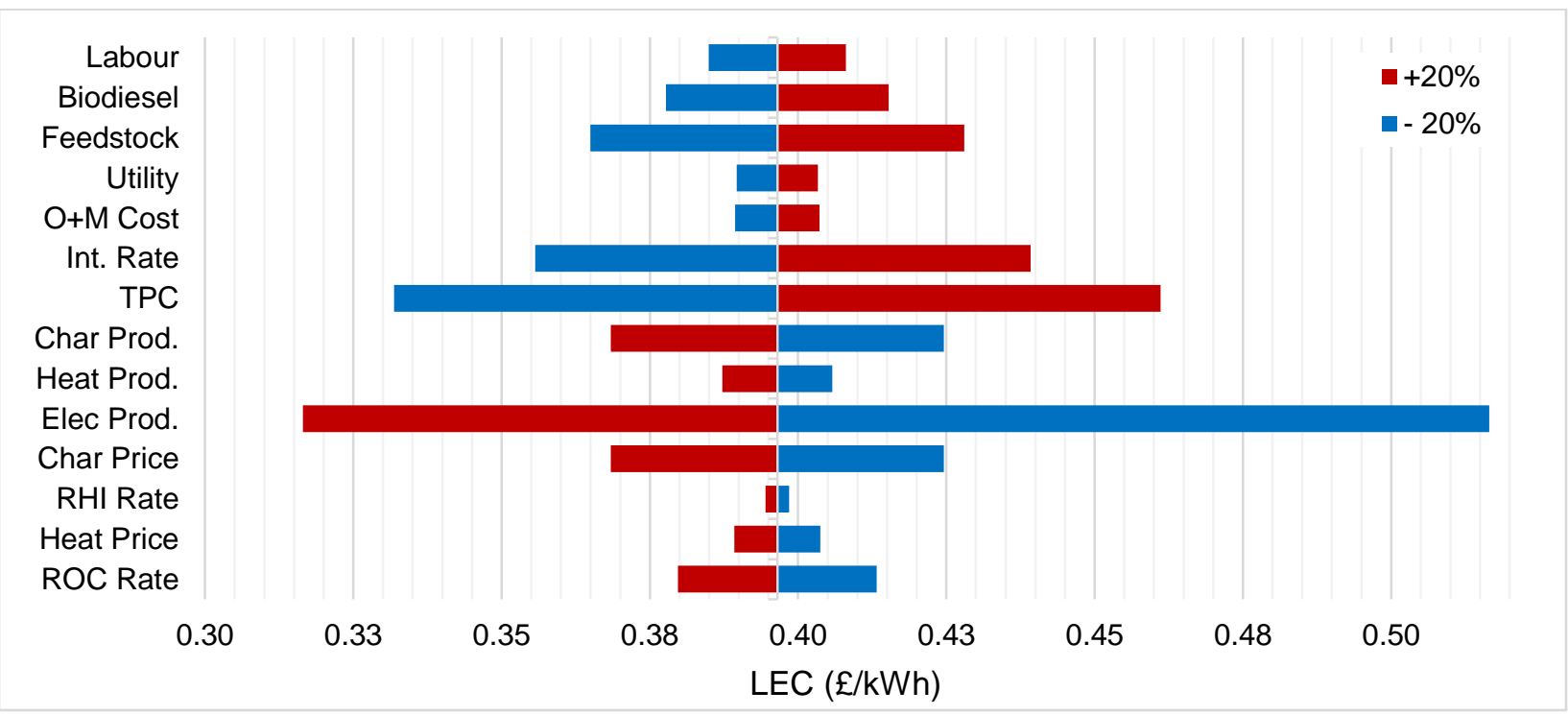

Figure 6. Sensitivity analysis for calculated LEC (based on $1000 \mathrm{~kg} / \mathrm{h}$ system) 
It is seen that all variables show linear behaviour except electricity productivity, which has the highest impact. A decrease of $20 \%$ electricity productivity results in $30.3 \%$ rise in LEC, and an increase of $20 \%$ electricity productivity causes a $20.2 \%$ reduction in LEC. In reality, such a substantial increase in the electrical efficiency is impractical, as the existing diesel engine arrangement is maturely established and it is extremely difficult achieve an electrical efficiency of over $45 \%$. It is still possible to optimise the pyrolysis process towards higher yields of pyrolysis oil so the overall system electrical efficiency can be increased. However, this would probably cause a reduced yield of char, which would tend to increase the LEC. The TPC is the second most sensitive variable in the LEC, followed by the capital loan interest rate chosen, which determines the annual capital repayment. Interest rate is to some extent negotiable with lenders but only over a narrow range. In industrial application, the project developer should endeavour to reduce these capital related costs, as this has the highest impact to the project's financial viability. Feedstock cost is the largest expenditure in the operating costs and therefore has a very high impact on LEC. Project developers could consider cheaper feedstocks with similar characteristics to wood pellets, such as wood chip and sawdust. However this should take into consideration of the impact of feedstock on the quality of pyrolysis products and consequently CHP efficiency. The consumables costs, including feedstock and biodiesel, are highly sensitive to changes in the market and can vary enormously. It is worth noting that the intermediate pyrolysis system has also been shown to be effective in processing waste materials with zero or negative cost (gate fee) to produce high quality pyrolysis oils [20], so it may be possible to demonstrate viable operation using this type of feedstock. The heat productivity, sales revenue and the RHI rates have the lowest impact on the LEC due to the relatively low market value and limited incentive support for a system at this scale.

\subsubsection{Optimistic scenarios}

This section considers the market potential for Pyro-CHP systems under different scenarios. To show this the $1000 \mathrm{~kg} / \mathrm{h}$ system has been modelled. It is broadly accepted that the costs of a process reduce as more of the same units are built and experience accumulates in labour learning, process improvement, product standardisation, and economies of scale [37]. By applying learning effects and changes in consumable costs and product prices over the base case project cost, the future LEC can be modelled. For this analysis, a learning factor of $20 \%$ is assumed which will result in a $50 \%$ reduction in capital costs after 10 installations of a novel process [17]. The cost of feedstock has 
the second highest impact to the sensitivity of energy price following capital cost in the large-scale system (Section 5.2.1). To investigate the effect of using different type of feedstock on the LEC, an organic waste material collected with a gate fee of $£ 99 / t$ is analysed (the medium rate as reported by the major UK's Energy from Waste facilities [80]). As additionally discussed in Section 5.2.2, the interest rate for the capital loan is subject to agreement with the lender, and the prices of biodiesel and char also are highly sensitive to the market. The char can be used on the land for soil amendment and carbon sequestration. Although the difference between biomass based charcoal and bio-char have been discussed extensively, most researchers agree that they are basically the same product despite their different intended utilisation and small differences in the feedstock thermal treatment temperatures [81]. The average UK bio-char market price is reported to be $£ 3.51 / \mathrm{kg}$ (converted from US\$5.06/kg [82]), which is at least 3 times higher than that of charcoal. For this analysis, five different scenarios (S1-5) are examined: feedstock collected with a gate fee (S1); 50\% reduction in TPC (S2); 50\% reduction in TPC and 20\% reduction in consumable costs (S3); 50\% reduction in TPC, 20\% reduction in material cost and 50\% increase in char price (S4), and; $50 \%$ reduction in TPC, $20 \%$ reduction in material costs, $50 \%$ increase in char price and $10 \%$ interest rate $(\mathbf{S 5})$.

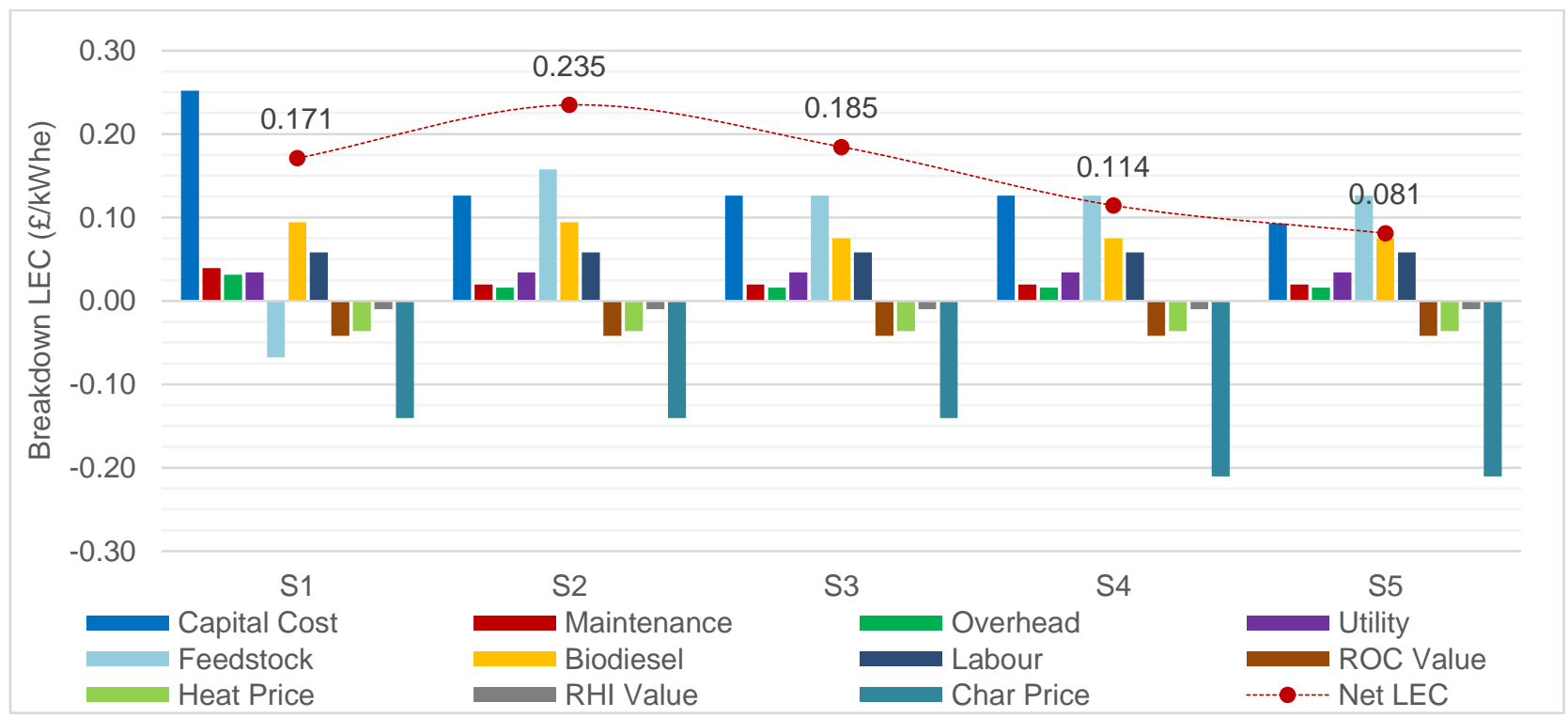

Figure 7. Breakdown of LEC under different scenarios (1000 kg/h system)

(S1: feedstock with a gate fee; S2: 50\% reduction in TPC; S3: 50\% reduction in TPC and 20\% reduction in material costs; S4: 50\% reduction in TPC, 20\% reduction in material cost and 50\% increase in char price; S5: 50\% reduction in TPC, $20 \%$ reduction in material costs, $50 \%$ increase in char price and $10 \%$ interest rate) 
Figure 7 illustrates the breakdown of LEC based on $1000 \mathrm{~kg} / \mathrm{h}$ system under five different scenarios. For S1, where a UK average waste-to-energy gate fee is applied to the feedstock, the LEC based on the current system could be significantly reduced by $56.8 \%$ to $£ 0.171 / \mathrm{kWhe}$. However, this theoretical value will not be realised in practice as a change of feedstock will result in a different yield of pyrolysis oil with different properties (density and heating values etc.) and consequently result in different energy efficiencies. In addition, waste material collected is likely to require further processing including drying and pelletising before fed into the pyrolysis reactor. For S2, where only a 20\% learning effect is applied to the future Pyro-CHP system (50\% reduction in TPC), the LEC can be reduced by $40.7 \%$ to $£ 0.235 / \mathrm{kWhe}$. With a further reduction of $20 \%$ in consumable costs (S3), the LEC can reduce further by $12.6 \%$ to reach $£ 0.185 / \mathrm{kWhe}$. Then if the wood-based char pellets were able to be used as a soil improver and at the same time a promising bio-char market were established, there could be a minimum 50\% price increase added to the current char price (S4). This will bring the LEC down to $£ 0.114 / \mathrm{kWhe}$. Finally, if in addition the project capital lenders agree to offer an interest rate of $10 \%$ (instead of the assumed 15\%) over the project lifetime (S5), the LEC can eventually be reduced to $£ 0.081 / \mathrm{kWhe}$. This value is low enough to make the project financially viable in comparison with the average industrial electricity selling price of $£ 0.1001 / \mathrm{kWhe}$. S5 is a highly optimistic scenario, but it indicates the required direction of development of the technology for the project developers.

\subsection{Life-cycle GHG emissions}

Life-cycle GHG emission analysis quantifies the real life overall system $\mathrm{CO}_{2}$ e emissions covering the full life of the source, from raw material and fuel production through plant construction to operation and waste stream management. The results of the emissions analysis at the different scales are evaluated and compared in Figure 8. Two different char application scenarios, bio-char farmland application and char co-firing for power generation, are compared here. GHG emissions from pyrolysis oils, the non-fossil part of biodiesel and char are renewable emission (GHG neutral) and hence are not counted as additional emissions to atmosphere. Carbon in bio-char for farmland application remains in the soil as stable carbon and hence is GHG negative. Therefore, the lifecycle GHG emissions of the system includes the emissions from fossil fuels used during the 
consumables (feedstock and biodiesel) production and transportation, the fossil part of the biodiesel and the emissions from the renewable biomass and (UCO-based) biodiesel used in the Pyro-CHP system.

The overall GHG emissions are very similar for the three plant capacities regardless different char application scenarios. This is because there is only slightly increased overall CHP efficiency for larger plants and consequently slightly less GHGs are emitted from the system. The overall GHG emissions (per unit of energy generated) for CHP + char co-firing is lower than those of CHP + char soil application, as there is more electricity generated by surplus char. However, the scenario of CHP + char soil application shows significantly lower net GHG emissions (approximately 0.05 $\mathrm{kgCO}_{2} \mathrm{e} / \mathrm{kWh}$ ), as the result of negative emission effect by carbon soil sequestration.

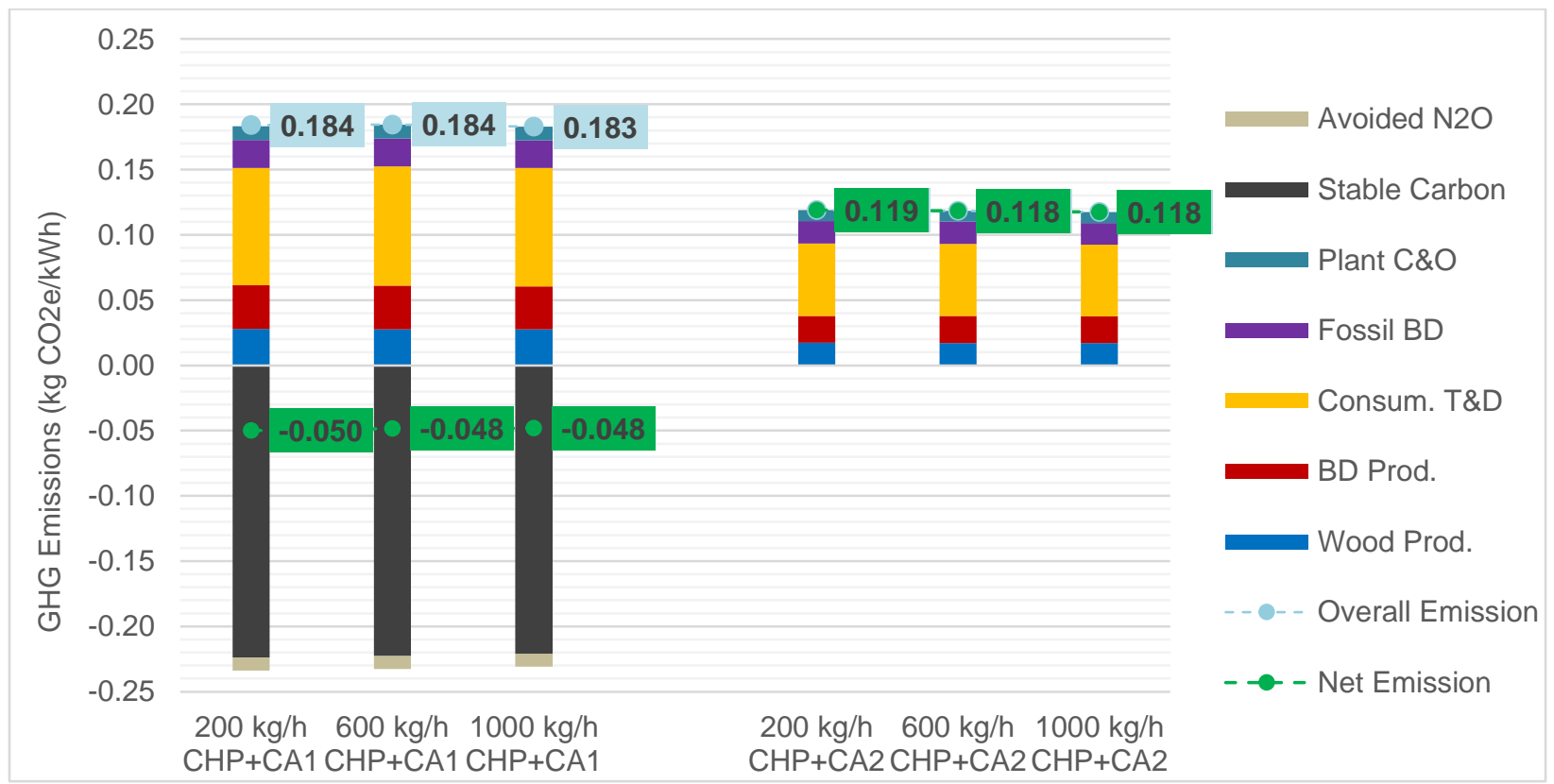

Figure 8. Life-cycle GHG emissions (CA1: char farmland application; CA2: char co-firing)

From Figure 8, it also interesting to see that, of the fossil emissions, consumables transportation and distribution is responsible for approximately $48 \% \mathrm{GHG}$ emissions (for both scenarios). This situation is mainly resulted from long distance transportation of the material by diesel-fuelled vehicles. Following this emission are those from biodiesel production and feedstock processing and production, being approximately $17.7 \%$ and $14.8 \%$ respectively. 


\subsection{Further comments}

The UK government has endeavoured to promote advanced thermal conversion and CHP technologies through fiscal incentives, such as RO and RHI, and through project capital grants. However governmental financial support cannot be a permanent feature of these schemes and they are most likely therefore to find application in market sectors to which they are particularly well suited. The best of these for the Pyro-CHP technology is where local (possibly off-grid) heat and power generation is desired, particularly using difficult feedstocks sourced as a waste by-product from other local activities and attracting a gate fee.

It is interesting to observe the importance of the char product in both economic and environmental performance. Compared to the mature electricity and heat markets, the markets for char and especially biochar are less well established and therefore highly sensitive to market factors. Further work should review the current and future markets for biochar as it significantly improves the case for Pyro-CHP systems.

Pyro-CHP schemes offer multiple environmental benefits and the promise of reduced energy costs. However for the technology to prosper, developers and innovators must continue to pursue improvements in char applications for higher value markets, safe utilisation of novel waste feedstocks, reactor cost reductions and improvements in liquid fuel yield, miscibility and quality.

\section{Conclusions}

This work presents the first comprehensive economic evaluation and life-cycle GHG emission analysis for a demonstration scale Combined Intermediate Pyrolysis and CHP (Pyro-CHP) system. The evaluation is carried out at system capacities of up to $1000 \mathrm{~kg} / \mathrm{h}$ wood pellets throughput (1.5 MW electrical or 3 MW CHP capacity).

The energy balance computed from the system performance model indicates that the overall CHP efficiency of the Pyro-CHP system is $42.5 \%$, with an engine subsystem CHP efficiency of $87.5 \%$ $(1000 \mathrm{~kg} / \mathrm{h}$ system). 
The results of the economic evaluation show that for the estimated project capital and operating costs, energy product prices and incentive rates, the levelised electricity cost (LEC) is about four times higher than the target market price for electricity, assuming that market rates are obtained for heat and char. Deployment of Pyro-CHP systems is therefore not economically viable under these estimations.

The benefits of scale are shown clearly in reducing plant operating costs, but are not seen to the same extent in project capital investment costs. This is largely due to the difficulty in scaling up the intermediate pyrolysis reactor in its current arrangement so that multiple reactors are required for plants over $200 \mathrm{~kg} / \mathrm{h}$.

The sensitivity analysis of the LEC indicates that energy efficiency, capital cost and feedstock price have the greatest impact and therefore should be the focus of further work if systems of this type are to be deployed. Using an organic waste based feedstock with negative cost instead of wood energy pellets has the potential to reduce LEC over 50\%. In addition, a hypothetical and optimistic scenario for future Pyro-CHP plants with 50\% reduced total plant cost (TPC), 20\% reduced material cost, $50 \%$ increased char selling price compared to the base case and $10 \%$ capital loan interest rate, would enable the system to become competitive in the current market, but this would however require much work.

The life-cycle GHG emission analysis shows that the proposed system has a strong positive environmental impact. If the bio-char produced in the system can be used for farmland application, the net GHG emissions for producing heat and power can be negative.

\section{Acknowledgments}

The authors acknowledge the funding and support from EPSRC SUPERGEN Programme under the Bioenergy Challenge Project EP/K036793/1. The research leading to the results of these work has received funding from the EU's Seventh Framework Programme (FP7/2007-2013/IAPP) under grant agreement number 286244. 


\section{Reference}

[1] IEA. 2015 Key World Energy Statistics. 2015.

[2] Dornburg V, van Vuuren D, van de Ven G, Langeveld H, Meeusen M, Banse M, et al. Bioenergy revisited: Key factors in global potentials of bioenergy. Energy Environ Sci 2010;3:258. doi:10.1039/b922422j.

[3] DECC. UK renewable energy roadmap update 2013. 2013.

[4] Tanaka Y, Mesfun S, Umeki K, Toffolo A, Tamaura Y, Yoshikawa K. Thermodynamic performance of a hybrid power generation system using biomass gasification and concentrated solar thermal processes. Appl Energy 2015;160:664-72. doi:10.1016/j.apenergy.2015.05.084.

[5] Paethanom A, Bartocci P, D' Alessandro B, D' Amico M, Testarmata F, Moriconi N, et al. A lowcost pyrogas cleaning system for power generation: Scaling up from lab to pilot. Appl Energy 2013;111:1080-8. doi:10.1016/j.apenergy.2013.06.044.

[6] Chun YN, Kim SC, Yoshikawa K. Pyrolysis gasification of dried sewage sludge in a combined screw and rotary kiln gasifier. Appl Energy 2011;88:1105-12. doi:10.1016/j.apenergy.2010.10.038.

[7] Slopiecka K, Bartocci P, Fantozzi F. Thermogravimetric analysis and kinetic study of poplar wood pyrolysis. Appl Energy 2012;97:491-7. doi:10.1016/j.apenergy.2011.12.056.

[8] Shen Y, Zhao P, Shao Q, Takahashi F, Yoshikawa K. In situ catalytic conversion of tar using rice husk char/ash supported nickel-iron catalysts for biomass pyrolytic gasification combined with the mixing-simulation in fluidized-bed gasifier. Appl Energy 2015;160:808-19. doi:10.1016/j.apenergy.2014.10.074.

[9] Brammer JG, Lauer M, Bridgwater AV. Opportunities for biomass-derived "bio-oil" in European heat and power markets. Energy Policy 2006;34:2871-80. doi:10.1016/j.enpol.2005.05.005.

[10] DECC. Climate change and energy - guidance: Combined heat and power. 2013.

[11] Kohl T, Laukkanen TP, Järvinen MP. Integration of biomass fast pyrolysis and precedent feedstock steam drying with a municipal combined heat and power plant. Biomass and Bioenergy 2014;71:413-30. doi:10.1016/j.biombioe.2014.09.014.

[12] Van De Beld B, Holle E, Florijn J. The use of pyrolysis oil and pyrolysis oil derived fuels in diesel engines for CHP applications. Appl Energy 2013;102:190-7. doi:10.1016/j.apenergy.2012.05.047.

[13] Chiaramonti D, Lidén G, Yan J. Advances in sustainable biofuel production and use. The XIX international symposium on alcohol fuels. Appl Energy 2013;102:1-4. doi:10.1016/j.apenergy.2012.09.021.

[14] BioPAD. Fortum Joensuu - Value adding by producing bio oil from wood. 2014.

[15] Shemfe MB, Gu S, Ranganathan P. Techno-economic performance analysis of biofuel production and miniature electric power generation from biomass fast pyrolysis and bio-oil upgrading. Fuel 2015;143:361-72. doi:10.1016/j.fuel.2014.11.078.

[16] Rogers JG, Brammer JG. Analysis of transport costs for energy crops for use in biomass pyrolysis plant networks. Biomass and Bioenergy 2009;33:1367-75. doi:10.1016/j.biombioe.2009.05.018.

[17] Bridgwater A V., Toft AJ, Brammer JG. A techno-economic comparison of power production by biomass fast pyrolysis with gasification and combustion. Renew Sustain Energy Rev 2002;6:181248. doi:10.1016/S1364-0321(01)00010-7.

[18] Kohl T, Teles M, Melin K, Laukkanen T, Järvinen M, Park SW, et al. Exergoeconomic assessment of CHP-integrated biomass upgrading. Appl Energy 2015;156:290-305. doi:10.1016/j.apenergy.2015.06.047.

[19] Kuppens T, Van Dael M, Vanreppelen K, Thewys T, Yperman J, Carleer R, et al. Technoeconomic assessment of fast pyrolysis for the valorization of short rotation coppice cultivated for phytoextraction. J Clean Prod 2015;88:336-44. doi:10.1016/j.jclepro.2014.07.023.

[20] Yang Y, Brammer JG, Ouadi M, Samanya J, Hornung A, Xu HM, et al. Characterisation of waste derived intermediate pyrolysis oils for use as diesel engine fuels. Fuel 2013;103:247-57. 
doi:10.1016/j.fuel.2012.07.014.

[21] Yang Y, Brammer JG, Mahmood ASN, Hornung A. Intermediate pyrolysis of biomass energy pellets for producing sustainable liquid, gaseous and solid fuels. Bioresour Technol 2014;169:7949. doi:10.1016/j.biortech.2014.07.044.

[22] Yildiz G, Ronsse F, Venderbosch R, Duren R van, Kersten SRA, Prins W. Effect of biomass ash in catalytic fast pyrolysis of pine wood. Appl Catal B Environ 2015;168-169:203-11. doi:10.1016/j.apcatb.2014.12.044.

[23] Yang Y, Brammer JG, Samanya J, Hossain AK, Hornung A. Investigation into the performance and emissions of a stationary diesel engine fuelled by sewage sludge intermediate pyrolysis oil and biodiesel blends. Energy 2013;62:269-76. doi:10.1016/j.energy.2013.09.058.

[24] Hossain AK, Ouadi M, Siddiqui SU, Yang Y, Brammer JG, Hornung A, et al. Experimental investigation of performance, emission and combustion characteristics of an indirect injection multi-cylinder CI engine fuelled by blends of de-inking sludge pyrolysis oil with biodiesel. Fuel 2013;105:135-42. doi:10.1016/j.fuel.2012.05.007.

[25] Warhurst AM, McConnachie GL, Pollard SJT. Characterisation and applications of activated carbon produced from Moringa oleifera seed husks by single-step steam pyrolysis. Water Res 1997;31:759-66. doi:http://dx.doi.org/10.1016/S0043-1354(97)80989-X.

[26] Yang Y. Energy production from biomass and waste derived intermediate pyrolysis oils. Aston University, 2014.

[27] Dornburg V, Faaij APC. Efficiency and economy of wood-fired biomass energy systems in relation to scale regarding heat and power generation using combustion and gasification technologies.

Biomass and Bioenergy 2001;21:91-108. doi:10.1016/S0961-9534(01)00030-7.

[28] Countrywide Farmers. Woodburner Wood Pellets 2015. http://www.countrywidefarmers.co.uk/pws/ProductDetails.ice?ProductID=10116 (accessed March 3, 2014).

[29] Sinnott RK. Chemical Engineering Design. vol. 6. 4th ed. Elsevier B.V.; 2005. doi:10.1016/S13858497(00)00184-4.

[30] ELEXON. ELEXON Guidance: Transmission Losses. 2013.

[31] Dalla Rosa A, Li H, Svendsen S. Method for optimal design of pipes for low-energy district heating, with focus on heat losses. Energy 2011;36:2407-18. doi:10.1016/j.energy.2011.01.024.

[32] DECC. Simple Guide to the CHP Quality Assurance (CHPQA) Programme. 2014.

[33] Anonymous. Economic Indicators. Chem Eng 2015;122:76.

[34] SKM Enviros. Analysis of characteristics and growth assumptions regarding AD biogas combustion for heat, electricity, and transport and biomethane production and injection to the grid. 2011.

[35] Brammer JG. Study of biomass gasifier-engine systems with integrated feed drying for power and CHP. Aston Univeristy, 2001.

[36] Rogers JG, Brammer JG. Estimation of the production cost of fast pyrolysis bio-oil. Biomass and Bioenergy 2012;36:208-17. doi:10.1016/j.biombioe.2011.10.028.

[37] Lieberman MB. The Learning Curve and Pricing in the Chemical Processing Industries. RAND J Econ 1984;15:213-28. doi:10.2307/2555676.

[38] Tijmensen M. Exploration of the possibilities for production of Fischer Tropsch liquids and power via biomass gasification. Biomass and Bioenergy 2002;23:129-52. doi:10.1016/S09619534(02)00037-5.

[39] Rogers JG. A techno-economic assessment of the use of fast pyrolysis bio-oil from UK energy crops in the production of electricity and combined heat and power. Aston University, 2009.

[40] Dimitriou I. Techno-economic assessment and uncertainty analysis of thermochemical processes for second generation biofuels. Aston University, 2013.

[41] IEA/NEA. Projected Costs of Generating Electricity- 2015 Edition. 2015.

[42] LC Energy. Pellets Price Matrix. 2015. 
[43] HM Revenue \& Customs. Business tax - Guidance for Fuel Duty. 2009.

[44] DECC. Gas and electricity prices in the non-domestic sector. 2015.

[45] Anglian Water. Tariffs and charges leaflet 2014-2015. 2014.

[46] Bovill D. Patterns of pay: Estimates from the annual survey of hours and earnings, UK, 1997 to 2013. 2014.

[47] Office for National Statistics. Annual survey of hours and earnings, 2015 provisional results. 2015.

[48] DECC. Electricity Generation Costs 2013. 2013.

[49] DECC. LSOA estimates of households not connected to the gas network 2014. 2016.

[50] Titirici M-M, White RJ, Falco C, Sevilla M. Black perspectives for a green future: hydrothermal carbons for environment protection and energy storage. Energy Environ Sci 2012;5:6796. doi:10.1039/c2ee21166a.

[51] Chen W-H, Hsu H-C, Lu K-M, Lee W-J, Lin T-C. Thermal pretreatment of wood (Lauan) block by torrefaction and its influence on the properties of the biomass. Energy 2011;36:3012-21. doi:10.1016/j.energy.2011.02.045.

[52] DECC. Government response to the consultation on proposals for the levels of banded support under the Renewables Obligation for the period 2013-17 and the Renewables Obligation Order 2012. 2013.

[53] DECC. Renewables Obligation banding levels: 2013-17. 2013.

[54] Ofgem. Renewables Obligation: Fuel Measurement and Sampling. 2014.

[55] Ofgem. Biodiesel, glycerol and the Renewables Obligation. 2009.

[56] Ofgem. Renewables Obligation: Biodiesel and fossil-derived bioliquids guidance. 2014.

[57] Greenergy. Perspective: Making biodiesel from by-products. 2011.

[58] e-Power. e-ROC track record. 2015.

[59] HM Revenue and Customs. Guidance: Climate Change Levy rates. 2015.

[60] Ofgem. Climate Change Levy (CCL) exemption. 2016.

[61] Ofgem. Tariffs that apply for Non-Domestic RHI for Great Britain. 2016.

[62] IPCC. Climate Change 2013: The Physical Science Basis. 2013. doi:10.1038/446727a.

[63] Zhang Y, Mckechnie J, Cormier D, Lyng R, Mabee W, Ogino A, et al. Life cycle emissions and cost of producing electricity from coal, natural gas, and wood pellets in Ontario, Canada. Environ Sci Technol 2010;44:538-44. doi:10.1021/es902555a.

[64] Zhang Y. Life Cycle Environmental and Cost Evaluation of Bioenergy Systems. University of Toronto, 2010.

[65] Alberici S, Toop G. UK biofuel industry overview. 2013.

[66] Defra. Greenhouse gas conversion factor repository. 2016.

[67] Defra. 2013 Government GHG conversion factors for company reporting: Methodology paper for emission factors. 2013.

[68] Hondo H. Life cycle GHG emission analysis of power generation systems: Japanese case. Energy 2005;30:2042-56. doi:10.1016/j.energy.2004.07.020.

[69] MacLeay I, Kevin H, Annut A. Digest of United Kingdom energy statistics 2015. 2015.

[70] Anglian Water. Greenhouse gas emissions annual report 2014. 2015.

[71] Severn Trent Water. Greenhouse gas (GHG) emission data for 2014-15. 2015.

[72] Lee JW, Hawkins B, Day DM, Reicosky DC. Sustainability: the capacity of smokeless biomass pyrolysis for energy production, global carbon capture and sequestration. Energy Environ Sci 2010;3:1695. doi:10.1039/c004561f.

[73] Gaunt JL, Lehmann J. Energy balance and emissions associated with biochar sequestration and pyrolysis bioenergy production. Environ Sci Technol 2008;42:4152-8. doi:10.1021/es071361i.

[74] Roberts KG, Gloy BA, Joseph S, Scott NR, Lehmann J. Life cycle assessment of biochar systems: Estimating the energetic, economic, and climate change potential. Environ Sci Technol 2010;44:827-33. doi:10.1021/es902266r.

[75] Yanai Y, Toyota K, Okazaki M. Effects of charcoal addition on N2O emissions from soil resulting 
from rewetting air-dried soil in short-term laboratory experiments: Original article. Soil Sci Plant Nutr 2007;53:181-8. doi:10.1111/j.1747-0765.2007.00123.x.

[76] Cayuela ML, Sanchez-Monedero MA, Roig A, Hanley K, Enders A, Lehmann J. Biochar and denitrification in soils: when, how much and why does biochar reduce N2O emissions? Sci Rep 2013;3:1732. doi:10.1038/srep01732.

[77] Li J, Brzdekiewicz A, Yang W, Blasiak W. Co-firing based on biomass torrefaction in a pulverized coal boiler with aim of 100\% fuel switching. Appl Energy 2012;99:344-54. doi:10.1016/j.apenergy.2012.05.046.

[78] Lantz M. The economic performance of combined heat and power from biogas produced from manure in Sweden - A comparison of different CHP technologies. Appl Energy 2012;98:502-11. doi:10.1016/j.apenergy.2012.04.015.

[79] Baliban RC, Elia JA, Floudas CA. Biomass to liquid transportation fuels (BTL) systems: process synthesis and global optimization framework. Energy Environ Sci 2013;6:267-87. doi:10.1039/C2ee23369j.

[80] WRAP. UK Gate Fees Report 2015. 2015.

[81] Verheijen F, Jeffery S, Bastos AC, Velde M van der, Diafas I. Biochar application to soil - A Critical Scientific Review of Effects on Soil Properties, Processes and Functions. 2009. doi:10.2788/472.

[82] Jirka S, Tomlinson T. 2013 State of the Biochar Industry- A Survey of Commercial Activity in the Biochar Field. 2014. 